\title{
Synthesis of Schiff Base Compounds from Vanillin and p-Aminoacetophenone Using Lime Juice as a Natural Acid Catalyst and Their Utilization as Corrosion Inhibitors
}

\author{
Laylatul Ma'rufah ${ }^{1, *}$ Ahmad Hanapi ${ }^{1,}$ Rachmawati Ningsih ${ }^{1,}$ A. Ghanaim Fasya ${ }^{1}$ \\ ${ }^{I}$ Chemistry Department, Science and Technology Faculty,, Universitas Islam Negeri Maulana Malik Ibrahim Malang, \\ $\mathrm{Jl}$. Gajayana 50 Malang, 65144, Indonesia \\ *Corresponding author. Email: 15630056@student.uin-malang.ac.id
}

\begin{abstract}
Schiff bases can be synthesized by reacting Vanillin and $p$-aminoacetophenone using a natural acid catalyst such as lime juice (Citrus aurantifolia.) with the grinding method. The purposes of this study were to determine the characterization. The yield of synthesized compounds calculated and also determined the physical properties such as color and melting point. The product also characterized using $\mathrm{NaOH}$ reaction. Further characterization was carried out using FTIR and ${ }^{1} \mathrm{H}-\mathrm{NMR}$. The synthesized compound is a yellow solid, slightly soluble in water, and has a melting point of 160-162 ${ }^{\circ} \mathrm{C}$. The Mass obtained is $1,9459 \mathrm{~g}$, with a percentage yield of 94,45\%. The compound 1- \{ 4 - [(4-hydroxy-3-methoxybenzylidene) -amino] -phenyl) -etanone reacts with $\mathrm{NaOH}$ to form a bright yellow color. This compound has an imine bond $\left(-\mathrm{C}=\mathrm{N}-\right.$ ), which showed in the wavenumber $1583 \mathrm{~cm}^{-1} .{ }^{1} \mathrm{H}-\mathrm{NMR}$ characterization showed a typical chemical shifting of $\mathrm{HC}=\mathrm{N}$ - at 8,5 ppm. The inhibition efficiency of these compounds ranged from $23,11-86,16 \%$.
\end{abstract}

Keywords: Schiff base, Vanillin, p-Aminoacetophenone, Grinding methods, Corrosion inhibitor

\section{INTRODUCTION}

Corrosion of material is worldwide issue that significantly affects natural in industrial environment. In 2017 the United States recorded a loss of \$ 276 annually due to corrosion [1].

Schiff bases in a compounds having an azomethine fungtional group has being widely accepted due to their cost effective starting materials, facile route of synthesis, low toxicity, high purity and environmental friendly [2]. In previous studies, it has been reported that Schiff bases are effective in inhibiting corrosion of steel, copper and aluminum[3-5]. Inhibitor solubility will increase in the presence of hydrophilic functional groups contained in a molecule[6]. so that the effectiveness of an organic substance as an inhibitor will depend on the structure of the compound[]].
Schiff base compounds can be synthesized conventionally by reflux method, using organic solvents and acid catalysts [8]. The conventional method has several disadvantages, such as low yield took a long time and produced hazardous waste to health and the environment [9]. This method is considered ineffective so that it is modified into an environmentally friendly method, such as using water solvents, grinding, and using natural catalysts known as green synthesis [10].

\section{METHODS}

\subsection{Schiff base synthesis}

The synthesis was carried out by grinding Vanillin $(7,5 \mathrm{mmol})$ and p-aminoacetophenone $(7,5 \mathrm{mmol})$ for 50 minutes with $0,25 \mathrm{~mL}$ lime juice as a natural acid 
catalyst. Then, the yield of the synthesized compound is calculated.

\subsection{Physical and Chemical Properties Test}

The synthesized compound is characterized physically, including its color and melting point. Chemical characterization was carried out by reacting to $0,002 \mathrm{mg}$ of the product in $5 \mathrm{~mL}$ of $2 \mathrm{M} \mathrm{NaOH}$.

\subsection{Characterization of Schiff Base Compounds}

Further characterization was carried out using FTIR (Fourier Transform Infrared) and ${ }^{1} \mathrm{H}-\mathrm{NMR}$ (Nuclear Magnetic Resonance).

\subsection{Corrosion Inhibitor Efficiency Test}

The test specimen preparation was carried out by cutting $2 \mathrm{~cm} \times 0,05 \mathrm{~cm}$ iron plates. Then the surface of the pieces of the iron plate was trimmed by sanding it.

Preparation of a stock solution of 10.000 ppm Schiff base corrosion inhibitor by dissolving 0,25 grams of Schiff's base in $0,5 \mathrm{~mL}$ of DMSO (2\%), then marking it with $1 \mathrm{M} \mathrm{HCl}$ to $25 \mathrm{~mL}$. The stock solution was made with a concentration variation of $2000 \mathrm{ppm} ; 3000 \mathrm{ppm}$; 4000 ppm; and 5000 ppm.

Test the Schiff base compound's efficiency as a corrosion inhibitor on metal cutter joyko L-150 in 1M $\mathrm{HCl}$ acid medium. then the percent inhibition efficiency is determined [2]:

$\% \mathrm{EI}=\frac{W o-W 1}{W o} \times 100 \%$

EI = Inhibitor Efficiency

$\mathrm{W}_{0}=$ Mass of iron without inhibitors

$\mathrm{W}_{1}=$ Mass of iron using inhibitors

\section{RESULT AND DISCUSSION}

\subsection{Schiff Base Synthesis}

Schiff base compound 1-(4-[(4-hydroxy-3-methoxybenzylidene)amino]phenyl)ethanone was synthesized using the grinding method with the addition of a natural acid catalyst in the form of lime juice by reacting Vanillin and p-aminoacetophenone. The grinding that is carried out will initiate the collision process between particles, so that energy transfer will occur and products will be formed. Forming the product occurs faster because of the heat caused by the friction that occurs during the grinding process [11][12]. the formation reaction of 1- (4-[(4hydroxy- 3- methoxy- benzylidene)- amino] -phenyl)ethanone is shown in figure 1.

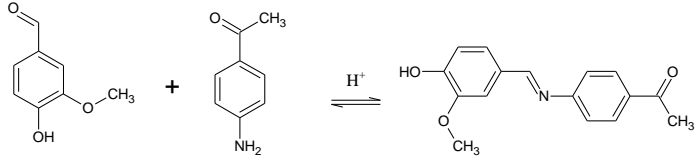

Figure 1. The scheme of Schiff base reaction

Table 1. Physical properties of the product

\begin{tabular}{llll}
\hline State & Vanilin & $\begin{array}{c}\text { p-Amino- } \\
\text { aetophenone }\end{array}$ & Product \\
\hline Physical form & Solid & Solid & Solid \\
Color & White & $\begin{array}{l}\text { brownish- } \\
\text { yellow }\end{array}$ & $\begin{array}{l}\text { Yellow } \\
\text { bright }\end{array}$ \\
Mass (g) & 1,1411 & 1,0138 & 1,9459 \\
\% yield & - & - & $94,45 \%$ \\
Melting point & $80{ }^{\circ} \mathrm{C}$ & $106{ }^{\circ} \mathrm{C}$ & $160-162{ }^{\circ} \mathrm{C}$ \\
\hline
\end{tabular}

\subsection{Chemical Properties Test with $\mathrm{NaOH}$}

Schiff base compound 1-\{4- [(4-hydroxy-3-methoxybenzylidene)-amino]-phenyl)-ethanone is a phenolic group that will react with $\mathrm{NaOH}$ to form $\mathrm{Na}$-phenolate. Phenolic compounds have - $\mathrm{OH}$ groups that will release $\mathrm{H}^{+}$and $\mathrm{NaOH}$, which will release $\mathrm{OH}^{-}$thus forming $\mathrm{Na}-$ phenolate that will soluble in water [13]. The reaction between the Schiff base compound and $\mathrm{NaOH}$ is shown in figure 2 .

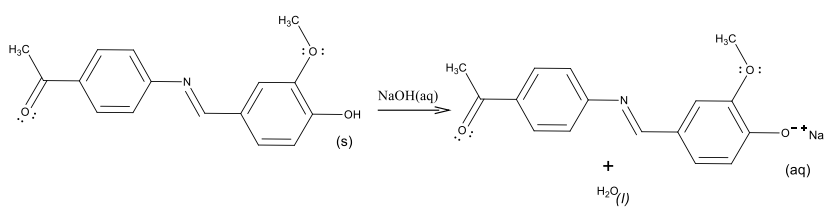

Figure 2. Bronsted-Lowry acid-base reaction

The solubility test results of the Schiff base compound 1- $\{4$ - [(4-hydroxy-3-methoxy-benzylidene) -amino] -phenyl) -ethanone are shown in Figure 3. Figure 3. (a) shows that the compound is insoluble in distilled water. This can be seen from the deposits found at the bottom of the test tube. Figure 3. (b) shows the Schiff base compound, which dissolves completely in $\mathrm{NaOH}$ and gives a bright yellow color. This color is formed due to the reaction between 1 - $\{4$ - [(4-hydroxy-3-methoxybenzylidene) -amino] -phenyl) -ethanone and $\mathrm{NaOH}$. 


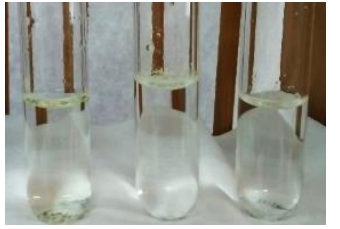

(a)

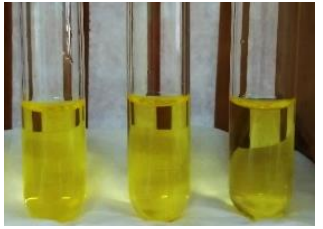

(b)
Figure 3. The solubility test results of Schiff base compound (a) distilled water (b) $\mathrm{NaOH}$.

\subsection{Product characterization}

\subsubsection{Characterization using FTIR}

The results of the characterization of synthetic products using FTIR obtained a unique absorption at a wavenumber of $1583 \mathrm{~cm}^{-1}$ [14], which is the absorption of the functional group $-\mathrm{C}=\mathrm{N}-$. This indicates that $1-\{4-$ [(4-hydroxy-3-methoxy- benzylidene)- amino]- phenyl)ethanone is formed. Besides, the typical absorption loss of $-\mathrm{NH}_{2}$ p-Aminoacetophenone and typical absorption $\mathrm{C}=\mathrm{O}$ vanillin in the region of wave numbers 3200-3400 $\mathrm{cm}^{-1}$ and $1700 \mathrm{~cm}^{-1}$, respectively, indicates that the reactants have reacted and formed new compounds.

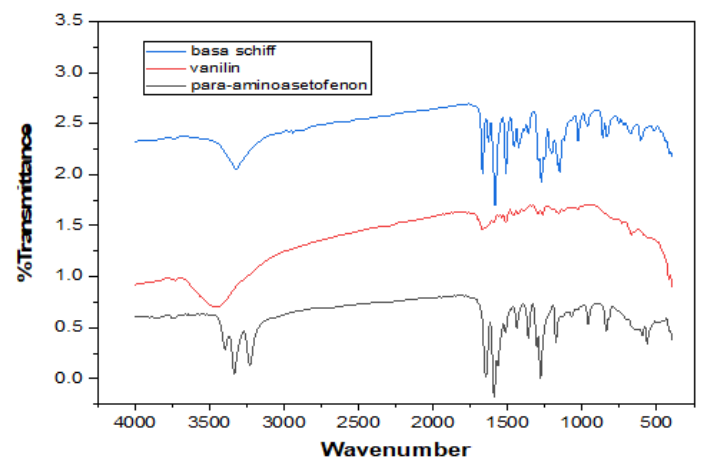

Figure 4. The results of FTIR spectra of products and reactants

\subsubsection{Characterization using ${ }^{1} \mathrm{H}-\mathrm{NMR}$}

Characterization using ${ }^{1} \mathrm{H}-\mathrm{NMR}$ produced 9 signals from the Schiff base compound 1- $\{4-$ [(4-hydroxy-3methoxy-benzylidene) -amino] -phenyl)-ethanone. Then in the chemical shift of $8.4722 \mathrm{ppm}$, there is a signal that shows the protons in the imine group [12]. Besides the signal from 1- $\{4$-[(4-hydroxy-3-methoxy-benzilidene) amino]-phenyl)-ethanone compounds on that spectra also found signals from reactants. In $(\delta) 6,0389 \mathrm{ppm}$ there is the typical signal of p-aminoacetophenone $\left(-\mathrm{NH}_{2}\right)$. Then in area $(\delta)$ 9,7622 $\mathrm{ppm}$ found $-\mathrm{COH}$ belonging to vanillin.

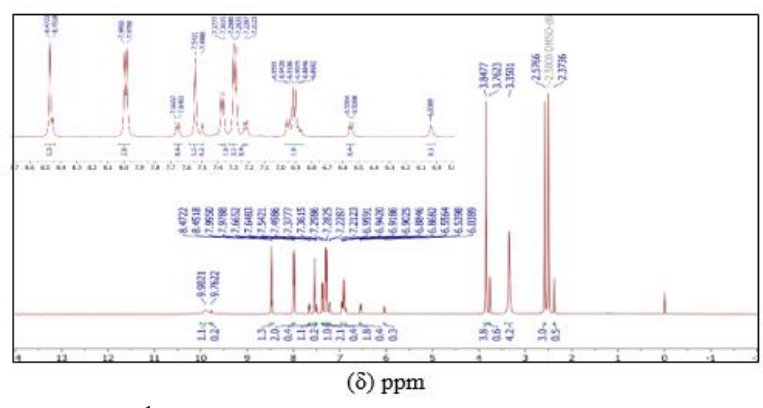

Figure 5. ${ }^{1} \mathrm{H}-\mathrm{NMR}$ spectra of Schiff base compound

Table 2. Interpretation of ${ }^{1} \mathrm{H}-\mathrm{NMR}$ spectra

\begin{tabular}{|c|c|c|c|c|}
\hline No & $\delta \mathrm{H}(\mathrm{ppm})$ & $\Sigma \mathrm{H}$ & Splitting & proton \\
\hline 1. & 2,3736 & $0,5 \mathrm{H}$ & $\mathrm{S}$ & $-\mathrm{CH}_{3}$ \\
\hline 2. & 2,5000 & & S & $\mathrm{DMSO}_{-} \mathrm{d}_{6}$ \\
\hline 3. & 2,5691 & $3 \mathrm{H}$ & S & $-\mathrm{COCH}_{3}$ \\
\hline 4. & 3,3501 & $4 \mathrm{H}$ & S & $-\mathrm{dCH}_{2}$ \\
\hline 5. & 3,7623 & $0,6 \mathrm{H}$ & $\mathrm{S}$ & $\mathrm{R}-\mathrm{O}-\mathrm{CH}_{3}$ \\
\hline 6. & 3,8475 & $3 \mathrm{H}$ & S & $-\mathrm{OCH}_{3}$ \\
\hline 7. & 6,0389 & $0,3 \mathrm{H}$ & S & $-\mathrm{NH}_{2}$ \\
\hline \multirow[t]{2}{*}{8.} & 6,5398 & $0,4 \mathrm{H}$ & $\mathrm{D}$ & $=\mathrm{CH}$ Aromatic \\
\hline & 6,5564 & & & \\
\hline \multirow[t]{2}{*}{9.} & 6,9070 & $1 \mathrm{H}$ & $\mathrm{D}$ & $=\mathrm{CH}$ Aromatic \\
\hline & 6,9232 & & & \\
\hline \multirow[t]{2}{*}{10.} & 7,2123 & $0,4 \mathrm{H}$ & $\mathrm{D}$ & $=\mathrm{CH}$ Aromatic \\
\hline & 7,2287 & & & \\
\hline \multirow[t]{2}{*}{11.} & 7,2745 & $2 \mathrm{H}$ & $\mathrm{D}$ & $=\mathrm{CH}$ Aromatic \\
\hline & 7,2905 & & & \\
\hline \multirow[t]{2}{*}{12.} & 7,3625 & $1 \mathrm{H}$ & $\mathrm{D}$ & $=\mathrm{CH}$ Aromatic \\
\hline & 7,3787 & & & \\
\hline 13. & 7,4986 & $0,2 \mathrm{H}$ & $\mathrm{S}$ & $=\mathrm{CH}$ Aromatic \\
\hline 14. & 7,5434 & $1 \mathrm{H}$ & $\mathrm{S}$ & $=\mathrm{CH}$ Aromatic \\
\hline \multirow[t]{2}{*}{15.} & 7,6483 & $0,4 \mathrm{H}$ & $\mathrm{D}$ & $=\mathrm{CH}$ Aromatis \\
\hline & 7,6652 & & & \\
\hline \multirow[t]{2}{*}{16.} & 7,9717 & $2 \mathrm{H}$ & $\mathrm{D}$ & $=\mathrm{CH}$ Aromatic \\
\hline & 7,9878 & & & \\
\hline
\end{tabular}




\begin{tabular}{ccccc}
17 & 8,4631 & $1 \mathrm{H}$ & $\mathrm{S}$ & $-\mathrm{HC}=\mathrm{N}$ \\
18. & 9,7622 & $1 \mathrm{H}$ & $\mathrm{S}$ & $-\mathrm{COH}$ \\
19. & 9,8714 & $1 \mathrm{H}$ & $\mathrm{S}$ & $-\mathrm{OH}$ \\
\hline
\end{tabular}

Explanation: $\mathrm{s}=$ singlet

$\mathrm{d}=$ doublet

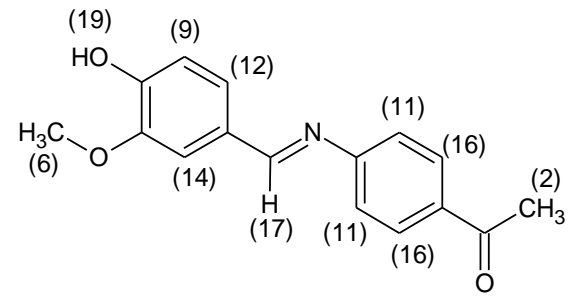

Figure 6. Suspected structure of Schiff base 1-\{4-[(4hydroxy-3-methoxy-benzylidene)-amino]-phenyl)ethanone.

\subsection{Corrosion Inhibitors}

Schiff bases have a long conjugation system that gives Schiff bases a more bond $(\pi)$ than the reactants. During the corrosion process, the iron plate will be positively charged to become $\mathrm{Fe}^{2+}$. The iron ion will interact with the PEB and $(\pi)$ bonds in the Schiff base compound form ion-dipoles, which will envelop the ferrous metal. So that the corrosion rate will be inhibited by the interaction that occurs [14]. The inhibition efficiency of Schiff 1- $\{4$ - [(4-hydroxy-3-methoxybenzylidene) -amino] -phenyl) -ethanone in hydrochloric acid solution is $23,11-86,16 \%$.

\section{CONCLUSION}

The synthesis of schiff base 1- (4 - [(4-hydroxy-3methoxy-benzylidene) -amino] -phenyl) -ethanone compound produces a product with the physical characteristics of a yellow solid, slightly soluble in water, and has a melting point of $160-162{ }^{\circ} \mathrm{C}$. The mass of the synthesis product produced was 1,9459 with yield $96,45 \%$. Characterization using an FTIR spectrophotometer resulted in a typical imine group spectra $(\mathrm{C}=\mathrm{N})$ at a wavenumber of $1583,909 \mathrm{~cm}^{-1}$. Characterization using ${ }^{1} \mathrm{H}-\mathrm{NMR}$ produced 9 signals of Schiff base. Then there is a chemical shift in the imine group at $8,4722 \mathrm{ppm}$. Inhibition efficiency in hydrochloric acid solution was $23,11-86,16 \%$.

\section{ACKNOWLEDGMENTS}

Gratefully acknowledge of financial support from the Indonesian Ministry of Religion Affairs (Kemenag) and Research and Community Services Institute (LP2M) of State Islamic University of Maulana Malik Ibrahim Malang.

\section{REFERENCES}

[1] Indocor. Indonesian Corrosion Association. Seminar Korosi, 2017.

[2] S. Chitra, K. Parameswari and A. Selvaraj, Dianiline Schiff Bases as Inhibitors of Mild Steel Corrosion in Acid Media, International Journal Electrochemistry, pp 5: 1675-1697, 2010.

[3] S. Bilgic, N. Caliskan, An investigation of some Schiff bases as corrosion inhibitors for austenitic chromium-nickel steel in $\mathrm{H}_{2} \mathrm{SO}_{4}, \quad$ J. Appl. Electrochem, 31, pp 79-83, 2001.

[4] H. Shokry, M. Yuasa, I. Sekine, et al., Corrosion inhibition of mildsteel by Schiffbase compounds in various aqueous solutions: Part 1, Corros. Sci. 40, 1998.

[5] K.C. Emrgul and O. Atakol, Corrosion inhibition of iron in $1.0 \mathrm{M} \mathrm{HCl}$ solution with Schiff base compounds and derivatives. Mater. Chem. Phys, 83 , pp 373-379. 2004

[6] U.R. Evans, The Corrosion and Oxidation of Metals, Hodder Arnold, 1976.

[7] A. Asan, a asa alo `lu, M.; Işı lan, M.; 1lıç, Z. Corrosion inhibition of rass in presence of terdentate ligands in chloride solution. Corros. Sci, 47, pp 1534-1544, 2005.

[8] A.J.A. Ghani, dan A.M.N Khaleel, Synthesis and Characterization of New Schiff Bases Derived from N (1)-Substituted Isatin with Dithiooxamide and Their $\mathrm{Co}(\mathrm{II}), \mathrm{Ni}(\mathrm{II}), \mathrm{Cu}(\mathrm{II}), \mathrm{Pd}(\mathrm{II})$, and $\mathrm{Pt}(\mathrm{IV})$ Complexes, Bioinorganic Chemistry and Applications, pp 1565-3633:12, 2009.

[9] M. Zarei and Jarrahpour, A Green and Efficient Synthesis of Azo Schiff Bases, Iranian Journal of Science \& Tsechnology, A, pp 235 - 242, 2011.

[10] V. K. Rao, S.S. Reddy, B.S. Krishna, et al., Synthesis of Schiff's Base in Aqueous Medium: A green Altrenative Approach with Effective Mass Yield and High Reaction Rates, Green Chemistry Letters and Reviews, pp 217-223, 2016.

[11]K. Tanaka, and R. Shiraishi, Clean and Efficient Condensation Reactions of Aldehydes and Amines in A Water Suspension Medium, Green Chemistry, 2, pp 272-273, 2000. 
[12] S. Sana, K.R. Reddy, K.C. Rajanna, et al., Mortar-Pestle and Microwave Assisted Regioselective Nitration of Aromatic Compounds in Presence of Certain Group V and VI Metal Salts under Sovent Free Conditions, International Journal of Organic Chemistry, 2, pp 233-247, 2012.

[13]R. Chang, Kimia Dasar Konsep-Konsep Inti Edisi Ketiga Jilid 2, Erlangga, 2005.
[14] U. Nazir, Z. Akhter, N. K. Janjua, et al., Biferrocenyl Schiff bases as efficient corrosion inhibitors for an aluminium alloy in $\mathrm{HCl}$ solution: a combined experimental and theoretical study $\uparrow$, RSC Adv., 10, pp 7585-7595, 2020.

[15] P.E. Aranha, P.S. Mirian, S. Romera, et al., Synthesis, Characterization, and Spectroscopic Studies of Tetradentate Schiff Base Chromium(III) Complexes, Polyhedron, 26, pp 1373-1382, 2006. 